\title{
Bond Dissociation Energies of Carbonyl Gold Complexes: a New Descriptor of Ligand Effects in Gold(I) Complexes?
}

Received 00th January 20xx, Accepted 00th January 20xx DOI: $10.1039 / \times 0 x \times 00000 x$ www.rsc.org/

\author{
David Gatineau, ${ }^{* a, b}$ Denis Lesage, ${ }^{b}$ Hervé Clavier, ${ }^{c}$ Héloïse Dossmann, ${ }^{b}$ Chen H. Chan, ${ }^{a}$ Anne Milet, ${ }^{a}$ \\ Antony Memboeuf, ${ }^{d}$ Richard B. Cole ${ }^{b}$ and Yves Gimbert, ${ }^{* a}$
}

\begin{abstract}
Ligand electronic effects in gold(I) chemistry have been evaluated by means of the experimental determination of M-CO bond dissociation energies for 16 [L-Au-CO ${ }^{+}$complexes, bearing L ligands widely used in gold catalysis. Energy-resolved analyzes have been achieved using tandem mass spectrometry with collision induced dissociation. Coupled to DFT calculations, this approach enables the quantification of ligand effects based on the LAu-CO bond strength. Further energy decomposition analysis gives access to detailed insights of this bond's properties. Whereas small differences are observed between phosphine- and phosphite-containing gold complexes, carbene ligands are shown to stabilize much more efficiently the gold-carbonyl bond.
\end{abstract}

\section{Introduction}

Homogeneous gold catalysis is a valuable tool for the straightforward preparation of a wide array of complex and structurally well-defined molecules from simple raw materials. ${ }^{1}$ The nature of the catalytic system plays an important role in enabling control of chemio-, regio- and stereoselectivities in synthesis. In particular, the ancillary ligand bound to the gold center is known to be a key parameter. Indeed, many examples reported in the literature highlight the fact that steric and electronic properties of ligands have direct impact upon the outcome of $A u(I)$ catalyzed reactions. ${ }^{2}$ Ligand effects in such catalytic reactions are usually discussed on the basis of electronic properties (e.g., a phosphine is considered to be electron rich, versus a phosphite, taken to be electron poor). However, the ability of gold to transmit electronic effects induced by a ligand is still under debate because $\mathrm{C}-\mathrm{O}$ stretching responses ${ }^{3}$ observed on known [LAu-CO] ${ }^{+}$complexes seem intriguing. Indeed, whatever the electronic nature of the ligand $\mathrm{L}$, the $\mathrm{C}-\mathrm{O}$ stretching responses in $[\mathrm{L}-\mathrm{Au}(\mathrm{I})-\mathrm{CO}]^{+}$complexes $\left(v_{\mathrm{CO}}\right)$, are systematically higher than the stretching frequency of free $\mathrm{CO}\left(v_{(\text {free-co })}=\right.$ $\left.2143 \mathrm{~cm}^{-1}\right)^{4,5}$ This feature was interpreted as a manifestation of the inability of the metal atom to contribute to $\mathrm{CO} \pi$-backdonation. The presence of intermolecular Au-Au interaction especially for ligands with little steric hindrance was also highlighted as a plausible explanation for this feature. ${ }^{6}$ In fact, $v_{\text {(co) }}$ values alone are not sufficient to conclude that $\pi$-backbonding makes a negligible contribution to the $\mathrm{M}-\mathrm{CO}$ bond. A theoretical description can also be used to refine the analysis of the M-CO bond. Thus, computational modelling, developed by Frenking et al., ${ }^{7 a}$ and more recently by Tarentelli and coworkers, $^{7 b}$ has shown that the Au-CO bond can be described

\footnotetext{
a. Univ. Grenoble Alpes and CNRS, DCM (UMR 5250) BP 53, 38041 Grenoble Cedex9 France.

b. Sorbonne Université, CNRS, Institut Parisien de Chimie Moléculaire, IPCM, 75005 Paris France.

c. Aix Marseille Univ. and CNRS, Centrale Marseille, iSm2, Marseille France.

d. Univ Bretagne Occidentale and CNRS, CEMACA (UMR 6521) 29238 Brest France.

E-mail: david.gatineau@univ-grenoble-alpes.fr; yves.gimbert@univ-grenoble-

alpes.fr.

Electronic Supplementary Information (ESI) available: [details of any supplementary information available should be included here]. See
} DOI: $10.1039 / x 0 x \times 00000 x$ by three distinct contributions: electrostatic attraction, $\mathrm{CO} \sigma-$ donation and a significant $\mathrm{Au} \pi$-back-donation. The fact that the observed $v_{(\mathrm{co})}$ frequency is higher that of free $\mathrm{CO}$ is mainly due to the electric field generated by the cationic metal moiety on the polarization of the $\mathrm{C}-\mathrm{O}$ bonding orbitals. ${ }^{8}$ This polarization leads to such large changes in IR frequencies (hypsochromic effect) that it completely masks a possible back-donation contribution, making IR analysis delicate in this case. Thus, even though several improved theoretical tools have emerged in recent years, ${ }^{9}$ it would be nonetheless highly desirable to have a complementary experimental approach to IR that could reliably measure electronic properties of a ligand.

If the electronic environment of the metal center (modulated by the ligands) can affect the strength of a C-O bond through a balance between $\sigma$-donation and $\pi$-backdonation, clearly it also modifies the strength of the M-CO bond. It is therefore reasonable to expect changes in the bond dissociation energy (BDE) values, ${ }^{10}$ obtained for CO linked to the metal center, according to the electron-donating properties of the other ligand present. In this study, the first measurements of BDE's for $\mathrm{CO}$ loss from [L-Au-CO $]^{+}$complexes are presented, where $L$ represents various phosphines, phosphites and carbenes ligands. Such complex was selected for the following reasons: (i) the particular example of L-Au(I) complexes is of interest because experimental data are noticeably missing from the literature; (ii) the cationic nature of $\mathrm{Au}(\mathrm{I})$ complexes is perfectly adapted to charged species detection by mass spectrometry, (iii) the linear geometry of $\mathrm{Au}(\mathrm{l})$ complexes minimizes the influence of steric hindrance effects and (iv) the linear geometry also favours minimal rearrangement of the complex upon dissociation. In this work, we have thus investigated the relation between the LAu-CO bond strength and the ligand electronic effects for a series of $16 \mathrm{Au}(\mathrm{I})$ complexes (Chart 1 ). The experimental procedure employed to measure the BDEs is first presented. Results are then discussed and rationalized with the help of density functional theory (DFT) electronic structure calculations and energy decomposition analysis (EDA). 


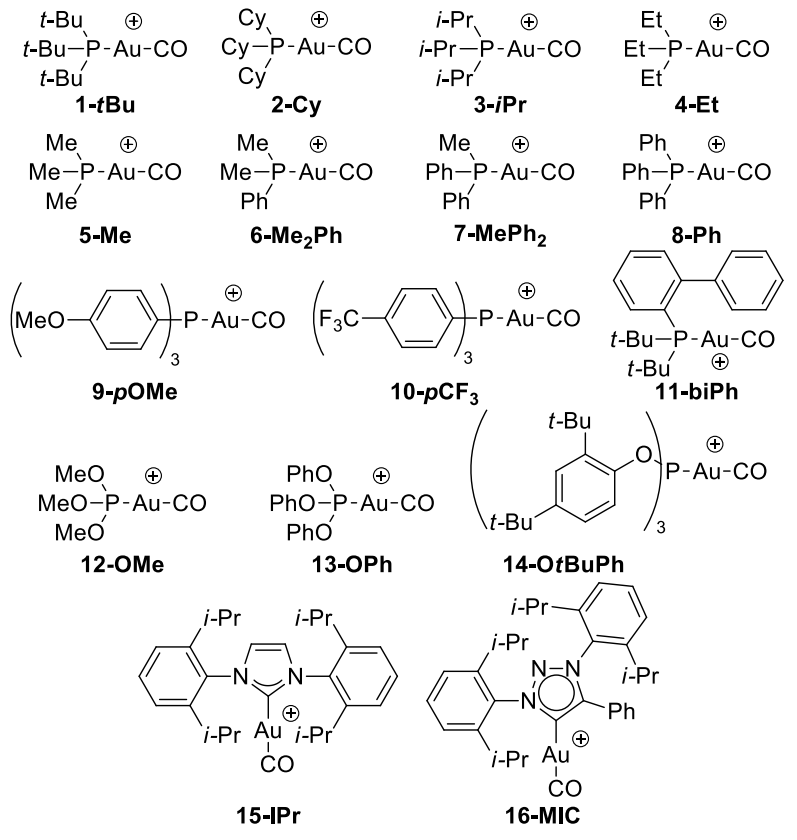

Chart $1 \mathrm{Gold}(\mathrm{I})$ carbonyl complexes studied in this work

\section{Results and discussion}

\section{Semi-empirical critical energy measurements}

Very few experimental data are available concerning [L-Au(I)$\mathrm{CO}^{+}$complexes, mostly due to the fact that such compounds are not easy to prepare and are not easy to store. Thus, only a few well-defined gold(I) carbonyl complexes have already been described in the literature. ${ }^{11}$ All of them are bearing a bulky ligand, but are nevertheless found to be extremely sensitive to moisture and temperature (must be stored below $-20^{\circ} \mathrm{C}$ ). The notable absence of reports describing gold(I) carbonyl complexes with ligands that do not sterically hinder $\mathrm{CO}$ association/dissociation raises the question of the feasibility to synthesize and store a wide range of such complexes. For these reasons, we decided to produce complexes of interest directly in the gas phase, inside the mass spectrometer, starting from a precursor allowing a large variety in the choice of possible ligands.

Inspired by previous work of Colton et al. on cationic $\mathrm{Au}(\mathrm{I})$ phosphine complexes, ${ }^{12}$ we determined that it was possible to produce $[\mathrm{L}-\mathrm{Au}]^{+}$ions in the electrospray ionization (ESI) source starting from an initial solution of $[\mathrm{L}-\mathrm{Au}-\mathrm{Cl}]$. Just after the source, these ions may then react with CO molecule in the hexapole ion guide region (Scheme 1), leading thus efficiently to gas- phase [L-Au-CO $]^{+}$ions. ${ }^{13}$ In this work, gold-carbonyl species were prepared in the mass spectrometer.

A set ${ }^{14}$ of $[\mathrm{L}-\mathrm{Au}-\mathrm{CO}]^{+}$cationic complexes 1-16 was produced, mass-selected and then subjected to collision induced dissociation (CID) experiments with argon. The CO $\operatorname{loss}\left([\mathrm{L}-\mathrm{Au}-\mathrm{CO}]^{+} \rightarrow \mathrm{[L-Au}^{+}+\mathrm{CO}\right)$ dissociation pathway was observed and monitored. During the process, part of the kinetic energy of the precursor ion is converted into internal energy by collision with a neutral target gas. The survival yield



Scheme 1 Production of [L-Au-CO] ${ }^{+}$complexes directly in the gas phase inside the mass spectrometer followed by collision induced dissociation on argon.

SY of the precursor ions is defined by equation 1 and is obtained as a function of the energy uptake occurring during CID where $I_{(R+)}$ is the abundance of the reactant ions and $\Sigma I_{(P+)}$ is the sum of the abundances of product ions. ${ }^{15}$

$\mathrm{SY}=\mathrm{I}_{(\mathrm{R}+)} /\left[\mathrm{I}_{(\mathrm{R}+)}+\Sigma \mathrm{I}_{(\mathrm{P}+)}\right](1)$

Although the threshold CID technique is usually employed for BDE measurements, ${ }^{16}$ in our case threshold measurements on the latter complexes were not attainable. This was due to minor amounts $(<5 \%)$ of highly fragile, readily dissociating [L$\left.\mathrm{Au}(\mathrm{I})-\mathrm{N}_{2}\right]^{+}$complexes formed in the mass spectrometer (same $\mathrm{m} / \mathrm{z}$ as $[\mathrm{L}-\mathrm{Au}(\mathrm{I})-\mathrm{CO}]^{+}$species). Isotopic labelling experiments were also performed using ${ }^{13} \mathrm{CO}$ instead of $\mathrm{CO}$. Those experiment suggested the presence of highly fragile isocarbonyl complexes [L-Au(I)-OC] ${ }^{+}$(For more details, see supporting information). Instead, we worked under multiplecollision conditions and for the 16 selected complexes, sigmoidal curves of survival yield were obtained. In order to take into account the size effect, the kinetic energy of the reactant ion measured in the laboratory frame ( $\left.E_{\text {lab }}\right)$ was converted into the center-of-mass energy $E_{\mathrm{CM}}$ using equation $2, \mu$ being the reduced mass $\left(\mu=M_{T} /\left(M_{T}+M_{R}\right)\right)$.

$E_{\mathrm{CM}}=\mu E_{\mathrm{lab}}(2)$

This center-of-mass energy defines the maximum energy transferred during an inelastic collision where $M_{R}$ and $M_{T}$ are the masses of the reactant ion and the neutral target gas, respectively. For the 16 selected complexes, sigmoidal curves of survival yield as a function of $E_{\mathrm{CM}}$ are shown in Figure $1 \mathrm{a}$.

Because the studied complexes vary substantially in size (degrees of freedom (DOF) from 42 to 330 and mass (M) from 301 to $871 \mathrm{Da})$, the shapes of the survival yield curves are dramatically affected, and these new curves give only incomplete qualitative information concerning the Au-CO BDE. Thus, the use of kinetic model based on transition state theory (Rice-Ramsperger-Kassel-Marcus (RRKM) theory) ${ }^{17}$ and accurate knowledge of the amount of energy deposited during the collision processes ${ }^{18}$ are necessary to extract the critical energy $\left(E_{0}\right)$ from the experimental data. Note that the critical energy is the difference between the energy of formation of the transition state for dissociation and that of the precursor ion at $0 \mathrm{~K}$ whereas the BDE refers to the calculated change in the enthalpy of dissociation reaction at $0 \mathrm{~K}$. For fragmentation 

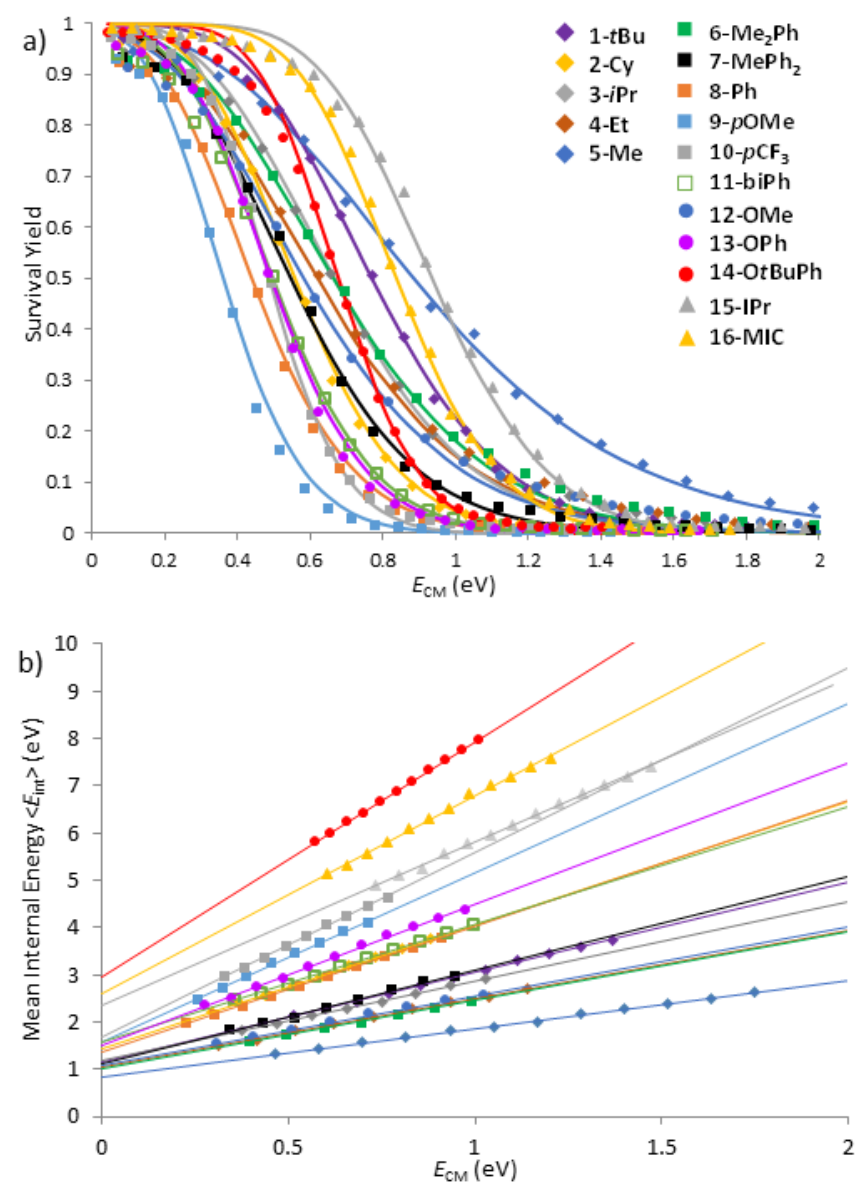

Figure 1 a) Survival yield (markers show experimental data and lines, RRKM modelling) and b) corresponding mean internal energy prior to decomposition $\left(\left\langle E_{\text {int }}\right\rangle\right)$ of the $\mathrm{CID}$ process for the 16 gold-carbonyl complexes as a function of the center-of-mass energy $\left(E_{\mathrm{CM}}\right)$.

processes without reverse activation barriers and without a kinetic bottleneck, these two values are very close and may be considered to be approximately equal in value. In this manuscript, BDE will refer to the calculated values and $E_{0}$ to the experimental measurements. The fact that the sizes of the studied systems are very different is a great challenge for critical energy measurements using mass spectrometric techniques. Accordingly, we propose here the use of an internal energy calibration to help measure critical energy values. For collisional activation under high pressure, a truncated Maxwell-Boltzmann internal energy distribution is often used. ${ }^{19}$ This simple model presumes a fast activation process and a slower kinetics of dissociation (for more details, see supporting information). ${ }^{19 a}$, $19 \mathrm{~d}$ Masskinetics software ${ }^{20}$ was used for RRKM modelling (Figures 1 and 2). Reference BDE, vibrational frequencies of the initial state, vibrational frequencies of the transition state and decomposition time inside the mass spectrometer were required inputs for these simulations and are described in the supporting information.

Using sigmoidal curves presented in Figure $1 \mathrm{a}$, the mean internal energies prior to fragmentation $\left(\left\langle E_{\text {int }}\right\rangle\right)$ were calculated and plotted as a function of center-of-mass energy $\left(E_{\mathrm{CM}}\right)$ for the 16 complexes studied (Figure $1 \mathrm{~b}$ ). As already described for this truncated Maxwell-Boltzmann internal energy distribution model, ${ }^{19 c-19 e}$ we obtained regression lines with slopes $\left(S_{<\text {Eint>/ECM }}\right)$ that showed dependence on the masses of the reactant $\left(M_{R}\right)$ (Figure 2a). Moreover, the origin of these lines gives the mean internal energy at $0 \mathrm{~V}\left(\left\langle E_{\text {int }}\right\rangle\right.$, ov $)$ which weakly depends on the DOF (Figure $2 b$ ), with a different trend observed for alkylphosphines 1-5. ${ }^{21}$

From these two empirical relations, general equations (3a) and $(3 \mathrm{~b})$ give the relation between the mean internal energy and the center-of-mass energy and could be defined for alkylphosphine gold complexes 1-5 (3b) and complexes 6-16 (3a).

$$
\begin{aligned}
& \left\langle E_{\text {int }}\right\rangle=(0.00790 \mathrm{DOF}+0.564)+E_{\mathrm{CM}}\left(0.00733 \mathrm{M}_{\mathrm{R}}-1.093\right)(3 \mathrm{a}) \\
& \left\langle E_{\text {int }}>=(0.00451 \mathrm{DOF}+0.690)+E_{\mathrm{CM}}\left(0.00733 \mathrm{M}_{\mathrm{R}}-1.093\right)(3 \mathrm{~b})\right.
\end{aligned}
$$

Equations ( $3 a$ ) and ( $3 b$ ) enable to obtain the deposited mean internal energy $<E_{\text {int }}>$ for each complex according to $E_{\mathrm{CM}}$. These $<E_{\text {int }}>$ are associated with corresponding characteristic temperatures $\left(T_{\text {char }}\right)$ which are internal energy distributions prior to decomposition (see SI for detail). These $\mathrm{T}_{\text {char }} v s$. $E_{\mathrm{CM}}$ values, obtained from this calibration, and the fit of the curves (Figure 1 ) allow to determine the critical energies $\left(E_{0}\right)$ for each complex (Table 1).

Uncertainties in the critical energies for the 16 gold complexes were estimated by varying parameters that influence the relative difference between these critical energies (see SI for detail). This calibration methodology, applied to 16 different
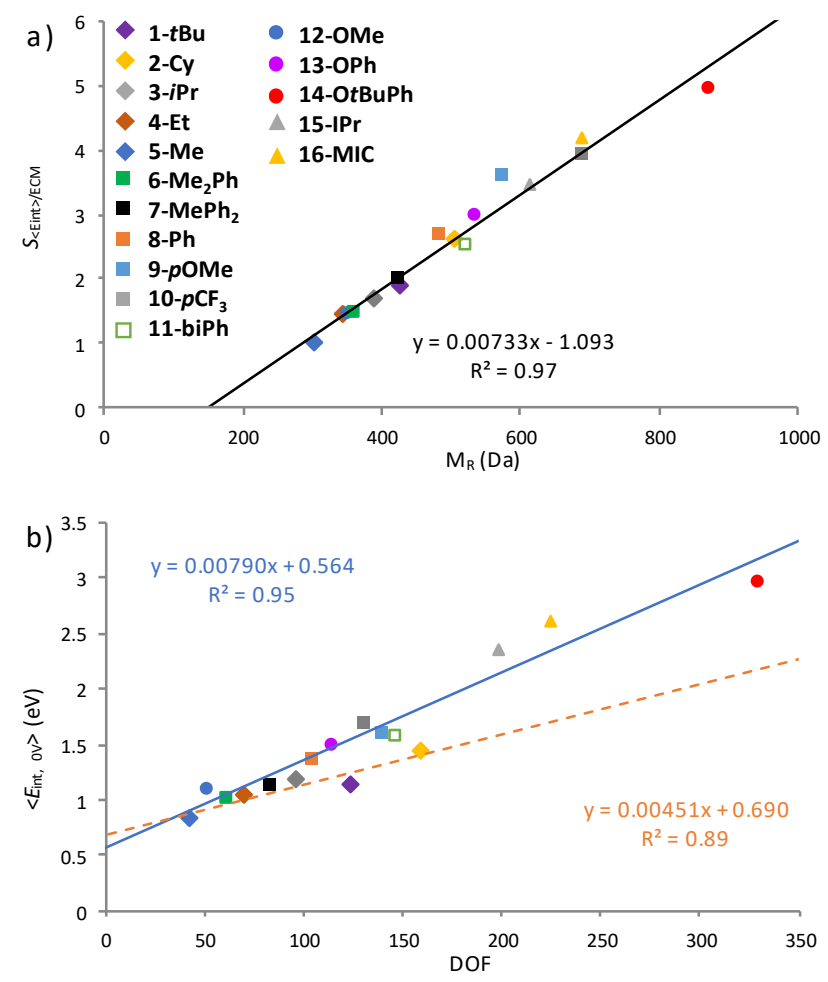

Figure 2 a) Slope of the calibration line $\left(S_{<\text {Eint }>/ E C M}\right)$ (from Figure $1 b$ ) as a function of the mass of the reactant $\left(M_{R}\right)$ with linear regression (line); b) Mean internal energy at $0 \mathrm{~V}$ collision $\left.\left(<\mathrm{E}_{\text {int, ov }}\right\rangle\right)$ as a function of the DOF of the 5 alkylphosphines gold complexes 1-5 with linear regression (dashed line) and 11 gold complexes 6-16 with linear regression (solid line). 
complexes, allows comparisons of critical energy values with good confidence concerning the range of the uncertainties.

\section{Computational details}

Geometry optimizations, frequencies and single point energy calculations were carried out at the PBEO-D3BJ22 level of calculation with the def2-TZVP23 basis set using Gaussian09 D01. ${ }^{24}$ Single point energy calculations were also performed at the DLNPO-CCSD $(T)^{25}$ (domain based local pair-natural orbital coupled-cluster) using ORCA 4.0.126 with the corresponding correlation consistent basis sets "CC-PVTZ-PP" 27 and for Au the relativistic ECP of the Stuttgart type was used. ${ }^{28}$ These level of calculations were chosen following the benchmark work of Kang et al. and Cavallo and co-workers ${ }^{29}$ (See supporting information for more details).

To gain more insight into the nature of the chemical bond between $[\mathrm{LAu}]^{+}$and [CO], we used the energy decomposition analysis (EDA) with the ADF package ${ }^{30}$ with BP86-D3BJ/TZ2P level of theory. Relativistic effects were taken into account via the zero-order regular approximation (ZORA) Hamiltonian. ${ }^{31}$

The EDA scheme allows the interaction energy to be divided into three terms as shown in equation (4):

$\Delta E_{\text {int }}=\Delta E_{\text {elect }}+\Delta E_{\text {Pauli }}+\Delta E_{\text {oi }}=\Delta E^{0}+\Delta E_{\text {oi. }}$ (4)

The first term, $\Delta E_{\text {elect, corresponds to the classical }}$ electrostatic interaction between the unperturbed charge distribution of the fragments and the second, $\Delta E_{\text {Pauli, }}$ term is the quantum repulsive Pauli interaction due to the antisymmetrization of the product of the wavefunctions of the fragments. The sum of the electrostatic interaction and the Pauli repulsion, $\Delta E^{0}$, allows an evaluation of the "ionic" contribution of the Au-CO bond. ${ }^{32}$ The last term, $\Delta E_{\mathrm{oi}}$, that can be identified as the covalent component of the bond, accounts for electron pair bonding, charge transfer (e.g., HOMO-LUMO

Table $1 \mathrm{CID}$ experimental critical energy $E_{0},{ }^{a}$ Computed $\mathrm{BDE}^{a}$ and selected calculated bonds $^{b}$ at PBEO-D3BJ/def2-TZVP level, cone angle $\theta^{c}$ for [L-Au-CO $]^{+}$complexes 1-16.

\begin{tabular}{lcccccc}
$\begin{array}{l}\text { Complex } \\
\text { [L-Au-CO }]^{+}\end{array}$ & $E_{0}$ & $\begin{array}{c}\text { Comp. } \\
\text { BDE }\end{array}$ & $\begin{array}{c}\text { Au-P } \\
\text { Au-C }\end{array}$ & Au-(CO) & Au(C-O) & $\theta$ \\
\hline 1-tBu & $35.2 \pm 1.5$ & 33.5 & 2.341 & 1.990 & 1.118 & 182 \\
2-Cy & $33.3 \pm 1.0$ & 33.4 & 2.334 & 1.991 & 1.118 & 170 \\
3-iPr & $33.5 \pm 1.2$ & 33.7 & 2.331 & 1.994 & 1.117 & 160 \\
4-Et & $33.2 \pm 1.3$ & 34.3 & 2.325 & 1.997 & 1.117 & 132 \\
5-Me & $37.7 \pm 2.0$ & 35.6 & 2.320 & 1.997 & 1.116 & 118 \\
6-Me2Ph & $36.3 \pm 1.6$ & 34.7 & 2.321 & 1.994 & 1.117 & 122 \\
7-MePh & $35.7 \pm 1.6$ & 34.3 & 2.323 & 1.992 & 1.117 & 136 \\
8-Ph & $33.5 \pm 1.4$ & 33.7 & 2.324 & 1.989 & 1.117 & 145 \\
9-pOMe & $31.4 \pm 1.7$ & 31.8 & 2.325 & 1.988 & 1.118 & 145 \\
10-pCF & $34.8 \pm 1.1$ & 35.1 & 2.322 & 1.993 & 1.116 & 145 \\
11-biPh & $34.0 \pm 1.7$ & 31.9 & 2.336 & 1.977 & 1.119 & - \\
12-OMe & $33.8 \pm 2.1$ & 35.7 & 2.308 & 2.003 & 1.116 & 107 \\
13-OPh & $34.9 \pm 1.5$ & 35.7 & 2.308 & 1.992 & 1.116 & 128 \\
14-OtBuPh & $36.9 \pm 1.4$ & 35.4 & 2.310 & 1.983 & 1.117 & 175 \\
15-IPr & $41.9 \pm 1.6$ & 43.6 & 2.023 & 1.948 & 1.119 & - \\
16-MIC & $40.6 \pm 1.8$ & 42.9 & 2.021 & 1.946 & 1.129 & -
\end{tabular}

${ }^{a}$ All energies are in $\mathrm{kcal} / \mathrm{mol},{ }^{b}$ bond lengths in $\AA{ }^{c}{ }^{c}$ Tolman cone angle in degree. ${ }^{3}$ interactions between fragments) and polarization (empty/occupied orbital mixing on one fragment due to the presence of another fragment). It can be decomposed using ETS-NOCV analysis (extended transition state-natural orbitals for chemical valence). ${ }^{33}$

This analysis reveals that only the first four components have significant eigenvalues. The first one corresponds to the $\sigma$ donation from the carbonyl to the gold fragment with charge depletion to the carbonyl and charge accumulation to gold and ligand $\left(\sigma_{1}\right)$. The next two components show depletion on the metal fragment and accumulation on the carbon of the carbonyl. It corresponds to $\pi$ back-donation from the d orbital of the gold to an unoccupied $\pi^{*}$ orbital of the CO $\left(\pi_{1}\right.$ and $\left.\pi_{2}\right)$. The last one could be considered as the $\sigma$ back-donation and is of less importance in our discussion due to small variations on the 16 studied complexes $\left(\sigma_{2}\right)$. Illustration of this analysis can be seen on figure 4 .

Moreover, we used the D3BJ dispersion correction, ${ }^{34}$ that is added to the interaction energy leading to the total interaction energy shown in equation (5):

$\Delta E_{\text {int }}=\Delta E_{\text {elect }}+\Delta E_{\text {Pauli }}+\Delta E_{\mathrm{oi}}+\Delta E_{\text {disp }}(5)$

The energy decomposition procedure was carried out on all the complexes described in this article and all ETS-NOCV results are detailed in the SI for this article.

\section{Ligand effect on Gold-carbonyl bond dissociation}

Figure $3 a$ shows the correlation plot obtained between semiempirical $E_{0}$ and calculated BDEs. A rather good agreement is obtained between these two sets of data $\left(r^{2}=0.81\right)$. The BDE values of the Au-CO bond span over $11.8 \mathrm{kcal} / \mathrm{mol}$ between the weakest and the strongest bond (Table 1, for complexes 9pOMe and 15-IPr, respectively) and reflect the variety of electronic effects of the set of studied ligands, which are ideally coordinated trans to the $\mathrm{CO} .{ }^{35}$ Rationalization of these effects was done with the help of the EDA analysis and a very good agreement could indeed be found between BDE and $\Delta E_{\text {int }}$ (figure $3 b$ ), which is consistent with a slight deformation of the fragments upon dissociation of the $\mathrm{CO}$. An exception is observed for complex $\mathbf{1 1}$ bearing a biphenyl moiety that can allow a second and close interaction with gold and deform the linear L-Au-CO torsion angle from $180^{\circ}$ to $175^{\circ}$ and increase the dispersion term, $\Delta E_{\text {disp }}$ (Table 2, entry 11). This interesting case will be discussed later.

In order to gain insight into the Au-CO bond dissociation, we decided to analyze our results along the ligand series: trialkylphosphines 1-5, $\mathrm{PMe}_{3-n} \mathrm{Ph}_{n} \quad(\mathrm{n}=0-3) \quad 5-8$, parasubstituted triphenylphosphine 8-10, phosphite $\mathrm{P}(\mathrm{OR})_{3} \mathbf{1 2 - 1 4}$ and carbene 15,16. Using experimental $E_{0}$, theoretical $\mathrm{BDE}$, calculated geometrical properties and EDA, some trends that strengthen the $\mathrm{Au}-\mathrm{CO}$ bond are rationalized and the new approach presented in this work is evaluated. 

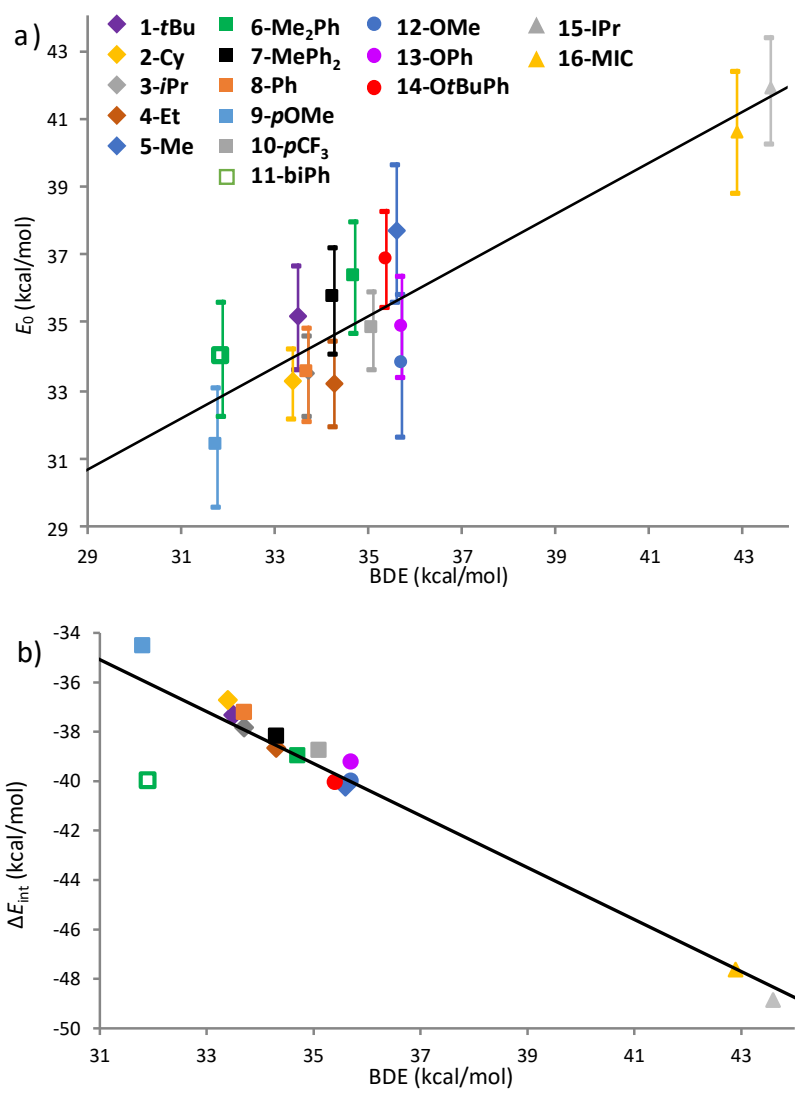

Figure 3 a) Correlation plot between the Au-CO BDEs and $E_{0}$ (values given in Table 1). b) Correlation plot between the LAu-CO BDEs and LAu-CO bond interaction energy $\Delta E_{\text {int }}$ on the basis of the values given in Table 1.

The electronic influence of trialkylphosphines $\left(\mathrm{PR}_{3}\right.$ complexes 1-5) was first studied. The $\mathrm{PR}_{3}$ global ability to increase electron density on a metal is expected to be directly related to the relative electron-donating abilities by inductive effect of the $\mathrm{R}$ groups, i.e. $\mathrm{Me}<\mathrm{Et}<i \mathrm{Pr} \approx \mathrm{Cy}<t \mathrm{Bu}$. However, when ranking these ligands according to the BDE of the $\mathrm{M}-\mathrm{CO}$ bond dissociation (Table 1, complexes 1-5), a different trend is observed: $t \mathrm{Bu} \approx \mathrm{Cy} \approx i \mathrm{Pr}<\mathrm{Et}<\mathrm{Me}$. From the $E_{0}$ values obtained by $\mathrm{CID} M S / M S$ experiments, no clear difference is observed, with the exception of 5-Me, whose $E_{0}$ is higher than the others in agreement with calculated $\mathrm{BDE}$. It seems that the $\mathrm{PMe}_{3}$ ligand is the most capable of the series to reinforce the strength of Au-CO bond. This agrees with calculated P-Au bond lengths: the shortest in the $\mathrm{PR}_{3}$ series is found for $\mathbf{5}-\mathrm{Me}(2.320$ $\AA$, table 1). ${ }^{36}$ Here, one might expect a correlation between larger $\mathrm{BDE}$ and shorter $\mathrm{Au}-(\mathrm{CO})$ bond length, but this relationship was not observed, ${ }^{37}$ as attested by a calculated value of $1.997 \AA$ for $\mathrm{PMe}_{3}$ versus $1.990 \AA$ for $\mathrm{PtBu}_{3}$. An analogous unexpected result was obtained for the $\mathrm{Au}(\mathrm{C}-\mathrm{O})$ bond: we expected a higher bond length for 5-Me (1.116 ̊̊) than for 1-tBu (1.118 $\AA$ ), but this was not found.

These results could be compared with those reported by Tyler et al. in a recent article concerning the steric and electronic influences of Buchwald-type alkyl-JohnPhos ligands. ${ }^{38}$ In that work on $\operatorname{LCr}(\mathrm{CO})_{5}$ complexes, it was shown that the net electron-donating ability of a phosphine is a balance between the intrinsic $\sigma$-donation and steric interactions. These contributing forces led to a ranking (determined by IR measurements) of the electron-donating ability of R-JohnPhos ligands: tBu-JohnPhos < Et-JohnPhos < iPr-JohnPhos < Cy-JohnPhos « Me-JohnPhos. In other words, it is not sufficient for a ligand to be electron rich, it also needs to be sufficiently close to the metallic center for an optimal transmission of the effects. Our results seem to point in the same direction; however, due to a strong electrostatic interaction, the explanation is different for gold cationic complexes. The decomposition of the interaction energy $\Delta E_{\text {int }}$ between $[\mathrm{LAu}]^{+}$and [CO] fragments into different contributions according to equation 4 could give some insight into the strengths of the metal-carbonyl bonds. The relative electron-donating abilities of the phosphine by inductive effect of the alkyl groups from Me to $t \mathrm{Bu}$ stabilized the electrostatic interaction of the Au-CO bond, $\Delta E_{\text {elect, }}$ from -110.1 to -115.5 $\mathrm{kcal} / \mathrm{mol}$ (Table 2, entries 1-5). However, in contrast to the protodeauration step study by Belanzoni and co-workers, ${ }^{39}$ the electrostatic contribution is quenched by the destabilizing Pauli repulsion term, going from 148.0 and $137.2 \mathrm{kcal} / \mathrm{mol}$ for 1-tBu and 5-Me respectively, and spanning an energy range of $10.8 \mathrm{kcal} / \mathrm{mol}$. The positive value of the "ionic" contribution $\left(\Delta E^{0}=\Delta E_{\text {elect }}+\Delta E_{\text {pauli }}\right)$ from 27.1 to $32.8 \mathrm{kcal} / \mathrm{mol}$ for $1-\mathrm{Me}$ and 4-Cy and respectively) indicates that the interaction between the gold cationic moiety and $\mathrm{CO}$ is destabilized due to steric repulsion $\left(\Delta E_{\text {Pauli }}\right)$ and corresponds approximately to one half of the covalent component $\left(\Delta E_{\mathrm{oi}} \approx-66 \mathrm{kcal} / \mathrm{mol}\right.$ ).

Another illustration of our approach is given in a second set of experiments comparing the behavior of complexes 5-8. In this series, Me groups are successively replaced by $\mathrm{Ph}$ groups forming ligands (L) of the type: $\mathrm{PMe}_{3-\mathrm{n}} \mathrm{Ph}_{\mathrm{n}}(\mathrm{n}=0-3)$. Both semiempirical $E_{0}$ and theoretical $\mathrm{BDE}$ values pertaining to the $\mathrm{Au}$ $\mathrm{CO}$ bond of [L-Au-CO] ${ }^{+}$complexes decrease monotonically in the order $\mathrm{PMe}_{3}>\mathrm{PMe}_{2} \mathrm{Ph}>\mathrm{PMePh}_{2}>\mathrm{PPh}_{3}$ (see Table 1, complexes 5-8), and despite the small variations recorded,

Table 2 EDA results of the Au-CO bond complexes 1-16. ${ }^{a}$

\begin{tabular}{lllllll}
$\begin{array}{l}\text { Complex } \\
\text { [L-Au-CO }]^{+}\end{array}$ & $\Delta E_{\text {int }}$ & $\Delta E_{\text {elect }}$ & $\Delta E_{\text {Pauli }}$ & $\Delta E_{\text {oi }}$ & $\Delta E^{0}$ & $\Delta E_{\text {disp }}$ \\
\hline 1-tBu & -37.3 & -115.5 & 148.0 & -67.0 & 32.4 & -2.8 \\
2-Cy & -36.7 & -115.5 & 148.3 & -66.9 & 32.8 & -2.7 \\
3-iPr & -37.8 & -113.3 & 144.1 & -66.0 & 30.8 & -2.6 \\
4-Et & -38.7 & -111.3 & 140.3 & -65.3 & 29.0 & -2.4 \\
5-Me & -40.2 & -110.1 & 137.2 & -65.1 & 27.1 & -2.2 \\
6-Me2Ph & -39.0 & -112.8 & 142.4 & -66.3 & 29.7 & -2.3 \\
7-MePh & -38.2 & -114.6 & 145.9 & -67.2 & 31.4 & -2.4 \\
8-Ph & -37.2 & -117.0 & 150.6 & -68.4 & 33.7 & -2.5 \\
9-pOMe & -34.5 & -120.3 & 158.4 & -70.1 & 38.1 & -2.5 \\
10-pCF & -38.8 & -114.3 & 145.6 & -67.5 & 31.2 & -2.5 \\
11-biPh & -40.0 & -121.2 & 155.3 & -69.3 & 34.1 & -4.8 \\
12-OMe & -40.0 & -108.5 & 135.1 & -64.4 & 26.6 & -2.3 \\
13-OPh & -39.2 & -114.6 & 145.2 & -66.9 & 30.6 & -2.9 \\
14-OtBuPh & -40.1 & -118.7 & 151.2 & -69.5 & 32.4 & -3.0 \\
15-IPr & -48.9 & -110.8 & 132.7 & -68.0 & 21.9 & -2.8 \\
16-MIC & -47.6 & -125.0 & 152.9 & -72.7 & 27.9 & -2.8
\end{tabular}

${ }^{a}$ All energies are in $\mathrm{kcal} / \mathrm{mol}$. 
calculations are in very good agreement with experiments. From a steric point of view, the size of the ligand increases, as attested by the evolution of $\theta$. Logically, the Au-P bond length slightly increases following the same trend, while the Au-(CO) distance is slightly shortened (see Table 1). As previously seen, the $\mathrm{Au}(\mathrm{C}-\mathrm{O})$ bond length seems minimally affected, and there is no obvious correlation between this inter-atomic distance and the BDE of the Au-CO bond. ${ }^{37}$ But the Au-P bond distance in this series is not the only parameter influencing the electronic effect. Indeed, in addition to the steric effect, if a phosphine with three Me groups is considered to be a $\sigma$-donor and a very weak $\pi$-acceptor, upon introduction of at least one aryl group on $\mathrm{P}$ the situation changes, allowing the phosphine to exhibit $\pi$-donor-acceptor properties. The progressive replacement of $\mathrm{Me}$ by $\mathrm{Ph}$ groups from 5 to $\mathbf{8}$ stabilizes the electrostatic interaction but, as observed previously for alkyl phosphine, the Pauli repulsion term overtakes those effects and the ionic contribution, $\Delta E^{0}$, have a good correlation with $\Delta E_{\text {int. }}$

Next, we sought to evaluate the influence of electron density on the aromatic ring of triphenylphosphine by introduction of electron donating (OMe) and electron withdrawing $\left(\mathrm{CF}_{3}\right)$ groups on para-position (complexes 9 pOMe and $10-p \mathrm{CF}_{3}$, respectively) in order to compare our results with the $\mathrm{CO}$ probe which is often used to investigate the electronic properties of ligands by observation of $v_{\mathrm{CO}}$ of metal-carbonyl complexes. For example the $v_{c o}$ frequencies reported for $\mathrm{P}\left(\mathrm{C}_{6} \mathrm{H}_{4}-p-\mathrm{OMe}\right)_{3}, \mathrm{PPh}_{3}, \mathrm{P}\left(\mathrm{C}_{6} \mathrm{H}_{4}-p-\mathrm{CF}_{3}\right)_{3}$ in complexes $\mathrm{FeCp}\left(\mathrm{SnPPh}_{3}\right)(\mathrm{CO})\left(\mathrm{PR}_{3}\right)^{40}$ are 1903, 1904 and 1914 $\mathrm{cm}^{-1}$, respectively, indicating that $\mathrm{P}\left(\mathrm{C}_{6} \mathrm{H}_{4}-p-\mathrm{CF}_{3}\right)_{3}$ is the most electron poor ligand of this series. ${ }^{41} \mathrm{By}$ comparison with this probe, we would expect a higher BDE for the 9-pOMe complex, bearing an electron rich phosphine which could offer electron density to the metal and allow higher $\pi$-retrodonation to $\mathrm{CO}$, compared to the $\mathbf{1 0}-\mathbf{p} \mathbf{C F}_{\mathbf{3}}$ complex, an electron poor phosphine. However, the computed BDE values go exactly in the opposite way, $31.8 \mathrm{kcal} / \mathrm{mol}$ for the 9-pOMe complex, against $35.1 \mathrm{kcal} / \mathrm{mol}$ for the $10-p \mathbf{C F}_{3}$ complex. The experimental CID measurements corroborate this difference, 31.4 vs $34.8 \mathrm{kcal} / \mathrm{mol}$. The $\mathbf{8}-\mathbf{P h}$ complex, in relation to $\mathrm{BDE}$ and $E_{0}$, lies between 9-pOMe and 10-p $\mathrm{CF}_{3}$ (BDE of 33.7 $\mathrm{kcal} / \mathrm{mol}, E_{0}$ of $33.5 \mathrm{kcal} / \mathrm{mol}$ ), following a logical trend: the more electron rich the ligand is, the lower the BDE is.

Clearly the explanation is not to be found in a steric hindrance effect, as evidenced by a similar cone angle value of $145^{\circ}$ for each of them. However, the explanation can be found using EDA. The electrostatic interaction is quite strong and follows the expected trend: the 9-pOMe complex bearing an electron-rich phosphine has a higher stabilizing contribution $\Delta E_{\text {elect }}(-120.3 \mathrm{kcal} / \mathrm{mol})$, than the $10-p \mathrm{CF}_{3}$ complex bearing an electron-poor phosphine $(-114.3 \mathrm{kcal} / \mathrm{mol})$ (Table 2 , entry 9 and 10 respectively). However, the "ionic" contribution is destabilized due to the steric repulsion ( $\Delta \mathrm{E}_{\text {pauli }}$ increases from 145.6 to $158.4 \mathrm{kcal} / \mathrm{mol}$ for $\mathbf{1 0 - p C F 3}$ and 9-pOMe, respectively) that overcomes the electrostatic contribution and a direct correlation between $\Delta E^{0}$ and $\Delta E_{\text {int }}$ nicely explain the Au-CO bond strength.
Considering the $t$ Bu-JohnPhos (11-biPh), by comparison with $\mathrm{PtBu}_{3}(\mathbf{1 - t \mathrm { Bu } )}$ we observe that upon replacing a $t \mathrm{Bu}$ group by a biaryl one, a small decrease of $E_{0}$ and $B D E$ values results. The augmented electron density offered to the metal by the biaryl group induces a stabilization of the electrostatic interaction by $5.7 \mathrm{kcal} / \mathrm{mol}$ compared to 1-tBu. The participation of the biaryl group on the dissociation of the AuCO bond explains the dispersion value $(-4.8 \mathrm{kcal} / \mathrm{mol}$, table 2 , entry 11), which is the lowest among the 16 complexes studied, and the modification of the PAuC angle from 180 to $176^{\circ}$ (see $\mathrm{SI}$ for details). However, the biaryl group is also responsible for the increase of $\Delta E_{\text {Pauli, }}$ and again the steric repulsion overcomes this stabilization, resulting in an overall weakening of the Au-CO bond.

Complexes incorporating phosphite ligands (12-14) have also been subjected to CID experiments. It is interesting to note that the computed BDE values for the loss of CO in [L-Au$\mathrm{CO}^{+}$is similar for $\mathbf{5 - M e}\left(\mathrm{L}=\mathrm{PMe}_{3} ; 35.6 \mathrm{kcal} / \mathrm{mol}\right)$ and $12-\mathrm{OMe}$ $\left(\mathrm{L}=\mathrm{P}(\mathrm{OMe})_{3} ; 35.7 \mathrm{kcal} / \mathrm{mol}\right)$. The small size (only 42 and 51 degrees of freedom for 5-Me and 12-OMe respectively) could explain a difference in the experimental $E_{0}$ values, but this difference becomes acceptable when uncertainties are taken into account. The energy decomposition analysis gives similar results with a small stabilization of the electrostatic interaction of the Au-CO bond with -110.1 and $-108.5 \mathrm{kcal} / \mathrm{mol}$ for phosphine and phosphite complexes, respectively, that indicates a small difference in the ability to transfer electron density to gold (trimethylphosphine vs. trimethylphosphite).

The situation is quite different with aryl substituents. The triphenylphosphine stabilizes the electrostatic interaction by $2.5 \mathrm{kcal} / \mathrm{mol}$ compared to triphenyphosphite (from - 117.0 to $114.6 \mathrm{kcal} / \mathrm{mol}$ for 8-Ph and $\mathbf{1 3 - O P h}$ respectively). However, the Tolman cone angle indicates a larger degree of steric hindrance for the phosphine than for the phosphite, and as already observed in the EDA results, the Pauli repulsion overcomes the electrostatic interaction and is higher for 8-Ph than for 13-OPh (Table 2, entry $\mathbf{1 3}$ and $\mathbf{8}$ ). It results in a stabilization of the Au-CO bond for the less donating ligand and the 13-OPh complex bearing a phosphite $(35.7 \mathrm{kcal} / \mathrm{mol})$ appears to be more stable than 8-Ph bearing a phosphine (33.7 kcal $/ \mathrm{mol})$.

For the three phosphite complexes 12-14, including the sterically hindered phosphite involved in 14- OtBuPh, the BDE and $E_{0}$ values are almost similar. The evolution of $\theta$ perfectly reflects the steric hindrance of the phosphite, but the Au-P bond distance is constant for the three complexes. Even if Pauli repulsion quenches the electrostatic interaction and destabilizes the Au-CO bond, on the contrary to other $P$ containing ligands, no correlation between $\Delta E^{0}$ and $\Delta E_{\text {int }}$ is observed.

In a last series, the case of ligands of the carbene family (complexes 15-IPr, 16-MIC), the influence on the dissociation energy of the Au-CO bond has been studied. BDEs as well as $E_{0}$ values differ significantly from those of the phosphorous ligands, being higher by more than $5 \mathrm{kcal} / \mathrm{mol}$ for computed values and $4 \mathrm{kcal} / \mathrm{mol}$ for experimental ones. This clearly shows the ability of these ligands to exchange electron density 
with gold, which has a visible effect on the lengths of Au-CO bonds. Indeed, in the case of carbenes, the Au-CO bond is shorter by $0.04 \AA$ (ca. $1.94 \AA$ ), compared to the phosphorous ligand series (ca. $1.98 \AA$ ). In considering the elongation of the $\mathrm{CO}$ bond that might be expected, in fact, this is less pronounced. Nonetheless, with 16-MIC ligand (1.129 ̊)), the elongation is appreciable compared with what is observed in the phosphine series (ca. $1.117 \AA$ ); this shows the strong $\sigma$ donating ability of this ligand. The 16-MIC complex also exhibits the lowest value of electrostatic interaction for the complete series that confirms the high donation potential of this ligand. On the contrary, the 15-IPr complex bearing the IPr carbene is not a strong $\sigma$-donor ligand with a lower stabilization of electrostatic interaction than 1-tBu ${ }^{42}\left(\Delta E_{\text {elect }}=-\right.$ 115.5 and $-110.8 \mathrm{kcal} / \mathrm{mol}$ for complexes 1-tBu and 15-IPr respectively). However, the 15-IPr complex is less destabilized by Pauli repulsion with only $132.7 \mathrm{kcal} / \mathrm{mol}$ which explains the strength of the Au-CO bond. The ETS-NOCV analysis shows the ability of carbene complexes to stabilize the $\pi$ back-donation components with lower values than phosphorus containing complexes and this is particularly true in the case of the 16MIC complex (see SI table S8). ${ }^{43}$

\section{Conclusions}

To summarize, we reported herein the formation of 16 complexes of the form [ $\mathrm{LAu}-\mathrm{CO}]^{+}$inside a modified triple quadrupole mass spectrometer from readily available $\mathrm{LAuCl}$ complexes. The decomposition of these complexes was investigated using high pressure CID. An empirical calibration, taking into account degrees of freedom and masses, was developed in order to allow comparisons of relative values with a good level of confidence. Experimental tendencies, albeit exhibiting only small differences in relative energies (critical energy differs by $10.5 \mathrm{kcal} / \mathrm{mol}$ between the least stable electron-rich phosphine complex 9-pOMe and the most stable carbene-containing complex $15-\mathrm{IPr}$ ), are in very good agreement with theoretical BDE calculations. This demonstrates the accuracy of the measurements carried out by $\mathrm{CID}$ on LAu(I)-CO complexes. From a chemical point of view, thanks to energy decomposition analysis of the Au-CO bond, some interesting trends can be drawn. I) electron-donating phosphines stabilize the electrostatic interaction of the Au-CO bond but it is overcome by Pauli repulsions thereby leading to the following conclusion: the less the phosphine is electron rich, the more the Au-CO bond is strengthened. II) no great BDE differences are observed between phosphines and phosphites. Thus, the dissociation of gold carbonyl complexes should not be used as the only descriptor to explain ligand effects observed in homogenous gold catalysis. III) The electronics properties of gold carbonyl complexes bearing carbene ligands differ significantly from phosphorus containing complexes, resulting in a strong stabilization of the Au-CO bond. In conclusion, although the experimental measurements of the absolute BDEs values for ligands is typically investigated by Blackbody Infrared Radiative Dissociation, ${ }^{44}$ we find that the relative $\mathrm{BDE}(\mathrm{Au}-\mathrm{CO})$ difference between $[\mathrm{L}-\mathrm{Au}-\mathrm{CO}]^{+}$complexes appears to be a good descriptor to classify the ligands according to their global electronic properties. This novel MS approach will be extended to other families of $A u(I)$ ligands using $\mathrm{CO}$, and also to other probes.

\section{Acknowledgements}

This work was supported by the ANR ELEEM2 project, grant ANR-13-BS07-0001 of the French Agence Nationale de la Recherche (postdoc funding of DG). This work was supported by the Labex Arcane (ANR-11-LABX-0003-01). We are very grateful to CNRS and UGA for their support. We warmly thank David Martin and Guy Bertrand for their generous gift of the $\mathrm{MICAuCl}$ complex.

\section{Notes and references}

1 For recent selected reviews: a) Modern Gold Catalyzed Synthesis (Eds.: A. S. K. Hashmi, F. D. Toste) Wiley-VCH, Weinheim, 2012. b) Gold Catalysis: An Homogneous Approach (Eds.: F. D. Toste, V. Michelet) Imperial College Press, London, 2014. c) R. Dorel, A. M. Echavarren, Chem. Rev., 2015, 115, 9028. d) L. Fensterbank, M. Malacria, Acc. Chem. Res., 2014, 47, 953. e) Y. Yang, A. D. Lackner, F. D. Toste, Acc. Chem. Res., 2014, 47, 889. f) L. Zhang, Acc. Chem. Res., 2014, 47, 877. g) A. S. K. Hashmi, Acc. Chem. Res., 2014, 47, 864.

2 For a review highlighting the role played by the ancillary ligand in Au-catalysed processes see: a) D. Gatineau, J.-P. Goddard, V. Mouries-Mansuy, L. Fensterbank, Isr. J. Chem., 2013, 53, 892. For selected examples, see: b) D. Ding, T. Mou, M. Feng, X. Jang, J. Am. Chem. Soc., 2016, 138, 5218. c) W. Rao, D. Susanti, B. J. Ayers, P. W. Chan, P J. Am. Chem. Soc., 2015, 137, 8131. d) R. K. Shiroodi, O. Koleda, V. A. Gevorgyan, J. Am. Chem. Soc., 2014, 136, 13146. e) G. Henrion, E. J. Chavas, X. Le Goff, F. Gagosz, Angew. Chem. Int. Ed., 2013, 52, 6277. f) W. Wand, G. B. Hammond, B. Xu, J. Am. Chem. Soc., 2012, 134, 5697. g) T. de Haro, E. GomezBengoa, R. Cribiu, X. Huang, C. Nevado, Chem. Eur. J., 2012, 18, 6811. h) F. Barabé, P. Levesque, I. Korobkovand, L. Barriault, Org. Lett., 2011, 13, 5580. i) M. Alcazaro, T. Stork, A. Anoop, W. Thiel, A. Fürstner, Angew. Chem. Int. Ed., 2010, 49, 2542 j) I. Alonso, B. Trillo, F. Lopez, S. Montserrat, G. Ujaque, L. Castedo, A. Lledos, J. L. Mascarenas, J. Am. Chem. Soc., 2009, 131, 13020. k) D. Benitez, E. Tkatchouck, A. Z. Gonzales, W. A. Goddard III, F. D.Toste, Org. Lett., 2009, 21, 4798.

3 F. A. Tolman, Chem. Rev., 1977, 77, 313.

4 For representative $\mathrm{L}-\mathrm{Au}(\mathrm{I})-\mathrm{CO}$ examples of, see: a) A. S. Romanov, M. Bochmann, Organometallics, 2015, 34, 2439. b) H. V. R. Dias, C. Dash, M. Yousufuddin, M. A. Celik, G. Frenking, Inorg. Chem., 2011, 50, 425. c) C. Dash, P. Kroll, M. Yousufuddin, H. V. R. Dias, Chem. Commun., 2011, 47, 4478. d) S. Martinez-Salvador, J. Forniés, A. Martin, B. Menjon, Angew. Chem. Int. Ed., 2011, 50, 6571. e) R. Kuster, K. Seppelt, Anorg. Allg. Chem., 2000, 626, 236. f) Q. Xu, Y. Imamura, M. Fujiwara, T. Souma, J. Org. Chem., 1997, 62, 1594. g) H. V. R. Dias, W. Jin, Inorg. Chem., 1996, 35, 3687.

5 An exception is observed for an $[\mathrm{L}-\mathrm{Au}(\mathrm{I})-\mathrm{CO}]^{+}$complex bearing an $o$-carborane diphosphine ligand developed by $M$. Joost, L. Estevez, S. Mallet-Ladeira, K. Miqueu, A. Amgoune and D. Bourissou, Angew. Chem., Int. Ed., 2014, 53, 14512.

6 M. A. Celik, C. Dash, V. A. Adiraju, A. Das, M. Yousufuddin, G. Frenking and H. V. R. Dias, Inorg. Chem., 2012, 52, 729. 
7 a) A. J. Lupinetti, G. Frenking, S. H. Strauss, Angew. Chem. Int. Ed., 1998, 37, 2113. b) G. Bistoni, S. Rampino, N. Scafuri, G. Ciancaleoni, D. Zuccaccia, L. Belpassi, F. Tarantelli, Chem. Sci., 2016, 7, 1174. c) S. H. Strauss, J. Chem. Soc. Dalton Trans. 2000, 1.

8 a) J. Velasquez, III, B. Njegic, M.S. Gordon, M.A. Duncan, J. Phys. Chem. A, 2008, 112, 1907. b) A. J. Lupinetti, S. Fau, G. Frenking, S. H. Strauss, J. Phys. Chem. A., 1997, 101, 9551. c) A. S. Goldman, K. Krogh-Jespersen, J. Am. Chem. Soc., 1996, 118, 12159.

9 a) For a recent development of computational approaches, see: D. Setiawan, R. Kalescky, E. Kraka, D. Cremer, Inorg. Chem., 2016, 55, 2332. b) R. Kaleschy, E. Kraka, D. Cremer, Inorg. Chem., 2014, 53, 478. c) For new descriptors derived from computational results on $\mathrm{L}-\mathrm{Au}-\mathrm{Cl}$ complex see: J. Jover N. Fey, J. N. Harvey, G. C. Lloyd-Jones, A. G. Orpen, G. J. J. Owen-Smith, P. Murray, D. R. J. Hose, R. Osborne, M. Purdie, Organometallics, 2010, 29, 6245.

10 For a recent study concerning the problems underlined about the pertinence of computed BDE, see: D. Cremer, E. Krafka, Dalton Trans., 2017, 46, 8323.

11 For a review on $\mathrm{Au}(\mathrm{CO})$ complexes, see: D. A. Rosca, J. A. Wright, M. Bochmann, Dalton Trans., 2015, 44, 20785. See also ref 4.

12 R. Colton, K. L. Harisson, Y. A. Mah, J. C. Traeger, Inorg. Chim. Acta, 1995, 131, 65.

13 For modified "home-made" Triple Quadrupole mass spectometer see: a) R. Thota, D. Lesage, Y. Gimbert, L. Giordano, S. Humbel, A. Milet, G. Buono, J.-C. Tabet, Organometallics, 2009, 28, 2735. b) D. Lesage, A. Milet, A. Memboeuf, J. Blu, A. E. Greene, J.-C. Tabet, Y. Gimbert, Angew. Chem. Int. Ed., 2014, 53, 1939.

14 Starting material, L-Au-Cl, commercially available or prepared using described procedure: for IPrAuCl preparation see a) P. de Frémont, N. M. Scott, E. D. Stevens, S. P. Nolan, Organometallics, 2005, 24, 2411. for MICAuCl preparation see b) D. R. Tolentino, L. Jin, M. Melaimi, G. Bertrand, Chem. Asian J., 2015, 10, 2139. See Supporting Information for details.

15 For an overview of ion activation methods, see: L. Sleno, D. A. Volmer, J. Mass. Spectrom., 2004, 39, 1091.

16 a) P. B. Armentrout, Top. Curr. Chem., 2003, 225, 233. b) M. T. Rodgers, P. B. Armentrout, Chem. Rev., 2016, 116, 5642. c) S. Narancic, A. Bach, P. Chen, J. Phys. Chem. A, 2007, 111, 7006.

17 a) O. K. Rice, H. C. Ramsperger J. Am. Chem. Soc., 1927, 49, 1617. b) L. S. Kassel J. Phys. Chem., 1928, 32, 225. c) R. A. Marcus, O. K. Rice J. Phys. Chem., 1951, 55, 894. d) R. A. Marcus J. Chem. Phys., 1952, 20, 359.

18 K. Vékey J. Mass Spectrom., 1996, 31, 445.

19 a) V. Gabelica, E. DePauw, Mass Spectrom. Rev., 2005, 24 566. b) L. Drahos, R. M. A. Heeren, C. Collette, E. De Pauw, K. Vékey J. Mass Spectrom., 1999, 34, 1373. c) J. Naban-Maillet, D. Lesage, A. Bossée, Y. Gimbert, J. Sztáray, K. Vékey, J.-C. Tabet J. Mass Spectrom., 2005, 40, 1. d) A. Pak, D. Lesage, Y. Gimbert, K. Vékey, J.-C.Tabet, J. Mass Spectrom., 2008, 43, 447. e) F. Ichou, A. Schwarzenberg, D. Lesage, S. Alves, C. Junot, X. Machuron-Mandard, J.-C. Tabet J. Mass Spectrom., 2014, 49, 498. f) F. Ichou, D. Lesage, X. Machuron-Mandard, C. Junot, R. B. Cole, J.-C. Tabet, J. Mass. Spectrom., 2013, 48, 179.

20 MassKinetics was used for RRKM modelling: L. Drahos, K. Vékey, J. Mass Spectrom., 2001, 36, 237.

21 This difference between alkylphosphine complexes and the others could be explaining with different initial energy depositions depending of number of "active" oscillators present in each complexes. For an evaluation of how "active" is the oscillator in peptide see a) L. Drahos, K. Vékey J. Am.
Soc. Mass Spectrom., 1999, 10, 323. and for a general correlation between size effect and fragmentation see b) $A$. Memboeuf, A. Nasioudis, S. Indelicato, F. Pollreisz, A. Kuki, S. Kéki, O. F. van den Brink, K. Vékey, L. Drahos Anal. Chem., 2010, 82, 2294.

22 a) S. Grimme, S. Ehrlich and L. Goerigk J. Comp. Chem. 2011, 32, 1456. b) A.D. Becke, E. R. Johnson J. Chem Phys., 2005, 122, 154101. c) E. R. Johnson, A. D. Becke J. Chem. Phys., 2005, 123, 024101. d) E. R. Johnson, A. D. Becke J. Chem. Phys., 2006, 124, 174104.

23 F. Weigend, R. Ahlrichs, Phys.Chem.Chem.Phys., 2005, 7 3297.

24 Gaussian 09, Revision D.01, M. J. Frisch, G. W. Trucks, H. B. Schlegel, G. E. Scuseria, M. A. Robb, J. R. Cheeseman, G. Scalmani, V. Barone, B. Mennucci, G. A. Petersson, H. Nakatsuji, M. Caricato, X. Li, H. P. Hratchian, A. F. Izmaylov, J. Bloino, G. Zheng, J. L. Sonnenberg, M. Hada, M. Ehara, K. Toyota, R. Fukuda, J. Hasegawa, M. Ishida, T. Nakajima, Y. Honda, O. Kitao, H. Nakai, T. Vreven, J. A. Montgomery, Jr., J. E. Peralta, F. Ogliaro, M. Bearpark, J. J. Heyd, E. Brothers, K. N. Kudin, V. N. Staroverov, R. Kobayashi, J. Normand, K. Raghavachari, A. Rendell, J. C. Burant, S. S. Iyengar, J. Tomasi, M. Cossi, N. Rega, J. M. Millam, M. Klene, J. E. Knox, J. B. Cross, V. Bakken, C. Adamo, J. Jaramillo, R. Gomperts, R. E. Stratmann, O. Yazyev, A. J. Austin, R. Cammi, C. Pomelli, J. W. Ochterski, R. L. Martin, K. Morokuma, V. G. Zakrzewski, G. A. Voth, P. Salvador, J. J. Dannenberg, S. Dapprich, A. D. Daniels, Ö. Farkas, J. B. Foresman, J. V. Ortiz, J. Cioslowski, and D. J. Fox, Gaussian, Inc., Wallingford CT, 2009.

25 a) C. Riplinger, F. Neese, J. Chem. Phys., 2013, 138, 034106 b) C. Riplinger, B. Sandhoefer, A. Hansen, F. Neese, J. Chem. Phys., 2013, 139, 134101.

26 F. Neese, WIREs Comput. Mol. Sci. 2012, 2, 73.

27 K. A. Peterson, C. Puzzarini, Theor. Chem. Acc., 2005, 114, 283.

28 D. Figgen, G. Rauhut, M. Dolg, H. Stoll, Chem. Phys., 2005, 311, 227.

29 a) R. Kang, H. Chen, S. Chaik, J. Yao, J. Chem. Theory Comput., 2011, 7, 4002. b) Y. Minenkov, E. Chermak, L. Cavallo, J. Chem. Theory Comput., 2015, 11, 4664.

30 a) T. Ziegler, A. Rauk, Theoret. Chim. Acta, 1977, 45, 1. b) F M. Bickelhaupt, E. J. Baerends, In: Reviews in Computational Chemistry Vol. 15; K. B. Lipkowitz, D. B. Boyd, Eds. (2000)

31 E. van Lenthe, A. Ehlers, E.-J. Baerends, J. Chem. Phys., 1999, 110, 8943.

32 G. Ricciardi, A. Rosa, I. Ciofini, A. Bencini, Inorg. Chem., 1999, 38, 1422.

33 M. Mitoraj, A. Michalak, J. Mol. Model., 2007, 13, 2

34 S. Grimme, S. Ehrlich, L. Goerigk, J. Comput. Chem., 2011, 32, 1457.

35 a) J. D. Atwood, in Inorganic and Organometallic Reaction Mechanism, $2^{\text {nd }}$ ed, (VCH Eds: Weinheim, 1997). b) B. J. Coe, S. J. Glenwright, Coord. Chem. Rev., 2000, 203, 5-80. c) R. B. Jordan in Reaction Mechanisms of Inorganic and Organometallic Systems, $3^{\text {rd }}$ ed. (Oxford University Press Inc: New York, 2007).

36 Note that, this correlation is also observed with uncharged $\mathrm{R}_{3} \mathrm{PAuCl}$ complexes (calculated P-Au bond of 2.229, 2.235, $2.245,2.248$ and $2.257 \AA$ for $\mathrm{R}=\mathrm{Me}, \mathrm{Et}, i \mathrm{Pr}, \mathrm{Cy}$ and $t \mathrm{Bu}$, respectively) and thus, it is independent of the charge of the complexes.

37 a) D. Cremer, A. Wu, A. Larsson, E. Kraka, J. Mol. Model. 2000, 6, 396. b) E. Kraka, D. Setiawan, D. Cremer, Journal of Computational Chemistry, 2016, 37, 130.

38 A. J. Kendall, L. N. Zakharov, D. R. Tyler, Inorg. Chem., 2016, 55, 3079. 
39 C. A. Gaggioli, G. Ciancaleoni, D. Zuccaccia, G. Bistoni, L. Belpassi, F. Tarantelli, P. Belanzoni, Organometallics, 2016, 35, 2275.

40 R. M. Mampa, M. A. Fernandes, L. Carlton, Organometallics, 2014, 33, 3283.

41 O. Gonzalez-Blanco, V. Branchadell, Organometallics, 1997, 16, 5556.

42 R. G. Carden, N. Lam, R. A. Widenhoefer, Chem. Eur. J., 2017, 23, 17992.

43 a) D. Munz, Organometallics, 2018, 37, 275. b) C. A. Gaggioli, G. Bistoni, G. Ciancaleoni, F. Tarantelli, L. Belpassi, P. Belanzoni, Chem. Eur. J., 2017, 23, 7558.

44 R. C. Dunbar, Mass Spectrometry Review, 2004, 23, 127. 